\title{
Revealing Prior-Austenite Grain Boundaries and Martensitic Structure of As-Quenched AISI 4140 Steel Treated by Plasma Electrolysis
}

\author{
L. Cenk Kumruoglu* and A. Özel \\ Dept. of Metallurgy and Materials Eng., Faculty of Engineering, Sakarya University, Sakarya, Turkey \\ The determination of prior-austenite grain size has been the subject of metallurgical research efforts for \\ many years. Metallurgical laboratories are often required to perform prior-austenite grain size determinations on \\ martensitic steel components that have been heat treated. Although these methods may occasionally be mandated \\ by material or procedural specifications, they are typically not preferred because they have a tendency of altering \\ the as-received microstructure. These processes can also be labour-intensive and costly. The goal of this work is \\ to chemically etch and identify the prior austenite grain size and martensitic structure of AISI 4140 steel treated \\ by plasma electrolysis. Polished samples were immersed in $60 \% \mathrm{HCl}, 30 \% \mathrm{HNO}_{3}, 5 \% \mathrm{HF}, 5 \% \mathrm{H}_{2} \mathrm{O}$ for 5 seconds \\ then immersed in $5 \%$ picric acid, $5 \% \mathrm{HCl}, 90 \%$ ethanol to reveal microstructures. Finally, the grain boundary and \\ lath martensitic structure were revealed.
}

DOI: $10.12693 /$ APhysPolA.123.404

PACS: 81.40.Gh, 81.40.-z, 81.65.Cf, 52.50.-b

\section{Introduction}

Plasma electrolytic surface hardening is a process that uses the heat generated by the cathodic hydrogen glow discharge on the surface of the ferrous materials to heat austenite phase, then the austenitized layers are transformed to martensite by switching off the electric potential. It covers several processes, based on cathalytical heating of a metallic substrate in an electrolyte, with the applied potential sufficiently high for electrical discharges to occur. A water-based alkaline electrolyte serves as a fluid electrode, as well as the plasma-generating (rapid heating $50-500^{\circ} \mathrm{C} / \mathrm{s}$ ) and cooling (quenching) environment. In this way, the heat affected zone on the work-piece becomes almost fully martensitic, producing a surface that can better withstand wear environments while minimizing distortion because of local heating $[1-5]$.

Plasma electrolytic heating is designed to rapid hardened and strengthened steels, by phase transformation of $\alpha$ (ferrite) to $\gamma$ (austenite) then $\gamma$ to $\alpha^{\prime}$ (martensite) [5]. Although martensitic microstructure can easily reveal by $2 \%$ nital etching, revealing prior-austenite grain boundaries has been one of the most difficult and frustrating tasks assigned to the metallography laboratory $[6,7]$. The difficulties of grain size and grain boundary measurement by chemical etching, carburizing, copper diffusion, oxidation and thermal etching in martensite specially carbon steels were reported [7].

Among varieties of prior-austenite grain revealing procedure, chemical etching is one of the most practical and widely implemented methods. This work is focused on the revealing grain boundaries of as-quenched martensite produced by plasma electrolysis.

*corresponding author; e-mail: lkumruoglu@sakarya.edu.tr

\section{Experimental studies}

All samples made from AISI 4140 steel with a diameter of $50 \mathrm{~mm}$ and thicknesses of $10 \mathrm{~mm}$ were rounded and polished. Temperature measurements had been performed using two $\mathrm{K}$ type thermocouples fixed in two holes of the samples at $2 \mathrm{~mm}$ distance from the heated surface. An aqueous solution was prepared with 12 $15 \mathrm{wt} \% \mathrm{Na}_{2} \mathrm{CO}_{3}$. The conductivity was varied between 88.7-91 mS and the $\mathrm{pH}$ was 10.7. The electrolyte temperature was varied between 19.5 and $20.5^{\circ} \mathrm{C}$. The plasma electrolytic device (PED) consisted of a power supply, aqueous solution tank made of stainless steel, circulation pump, manipulator, and metallic anode nozzle. The unit had a DC power supply, with $500 \mathrm{~V}, 100 \mathrm{~A}$ output capacity.

The experimental parameters of plasma electrolysis were given in Table. Rockwell $\mathrm{C}$ and microhardness tests were performed from the treated side (plasma surface) to the interface zone. A scanning electron microscopy (SEM) equipped with energy dispersive spectroscopy (EDS) was used for microstructure characterization of the hardened samples. The phase components of the treated samples were analyzed by X-ray diffraction (XRD) used by RIGAKU.

To examine hardened areas, section of samples were polished and etched gradually from 10 to $60 \mathrm{~s}$ in 2 to $10 \% \mathrm{HNO}_{3}$ and ethyl alcohol then studied using an optic microscopy. The $\mathrm{HNO}_{3}$ and viella reagent were the most preferably etchant for revealing martensite but unsuccessful for revealing prior-austenite grain size. Third etching route was as follows. Samples were etched with $3 \% \mathrm{HNO}_{3}$, then soaked in mix of $16 \mathrm{~g} \mathrm{CrO}_{3}+80 \mathrm{~g}$ $\mathrm{NaOH}+145 \mathrm{ml}$ deionized water at $120^{\circ} \mathrm{C}$. For each 30 min, all samples were dried and investigated. Because of the surface stains, revealing grain boundary was 
TABLE

Different experimental parameters such as applied voltages, thermal cycle variations were applied on substrates.

\begin{tabular}{c|c|c|c|c|c|c|c}
\hline \hline Sample & $\begin{array}{c}\text { Voltage } \\
{[\mathrm{V}]}\end{array}$ & $\begin{array}{c}\text { Heating } \\
\text { time [s] }\end{array}$ & $\begin{array}{c}\text { Tempera- } \\
\left.\text { ture [ }{ }^{\circ} \mathrm{C}\right]\end{array}$ & $\begin{array}{c}\text { HRC } \\
\text { max. }\end{array}$ & $\begin{array}{c}\text { HRC } \\
\text { avg. }\end{array}$ & $\begin{array}{c}D \\
{[\mathrm{~mm}]}\end{array}$ & $\begin{array}{c}H \\
{[\mathrm{~mm}]}\end{array}$ \\
\hline 1 & 260 & 16 & 423 & 57 & 56.3 & 24.5 & 3 \\
5 & 260 & 28 & 786 & 58 & 56.8 & 27.5 & 5 \\
6 & 300 & 6 & 120 & 11 & 9 & 0 & 0 \\
17 & 300 & 25 & 880 & 54 & 52.8 & 34 & 8 \\
18 & 320 & 6 & 170 & 11 & 10 & 0 & 0 \\
27 & 320 & 18 & 750 & 57 & 56.16 & 31 & 7 \\
\hline
\end{tabular}

$D$ - diameter of hardened zone and $H$ - depth of hardened zone.

not possible. Afterward, surface stains were gradually polished with silica solutions. The results were better than viella and nital variations but they need special care and careful polishing. As a result, $16 \mathrm{~g} \mathrm{CrO}_{3}+80 \mathrm{~g}$ $\mathrm{NaOH}+145 \mathrm{ml}$ deionized water bath etching method needs skillful person and is considered as time consuming and not reputable. In addition, $\mathrm{FeCl}_{3}+$ several acids were tried but these etching at tempts were also unsuccessful. Finally, mix of $5 \% \mathrm{HF}, 60 \% \mathrm{HCl}, 30 \%$ nitric acid, $5 \%$ distilled water was prepared, then samples were immersed in it during $5 \mathrm{~s}$. Then samples were cleaned in ethanol and soaked in mix of picric acid + ethanol + sodium dedosil sulfonate solution at $40^{\circ} \mathrm{C}$ during 1 to $10 \mathrm{~min}$. Finally, the etching route as written above gave favorable results for the samples which were heated to $450{ }^{\circ} \mathrm{C}$ and upper temperatures.

\section{Results and discussion}

Hardened zones were obtained on the plasma treated side, while in the middle of the sample it was the interface zone and, on the more interior side, a coarse pearlite was formed. At the austenite temperature on plasma side, the quenched layer end was cooled very rapidly, reaching the maximum hardness, hence the martensitic phase was formed on 4140 steel. This martensitic phase was revealed by macro etching (Fig. 1), Rockwell C (Table) and micro hardness (Fig. 2) testing. Then all hardened samples were chemically etched by solution whose details are given above. Prior austenite grain boundaries are given in Fig. 3 for several samples.
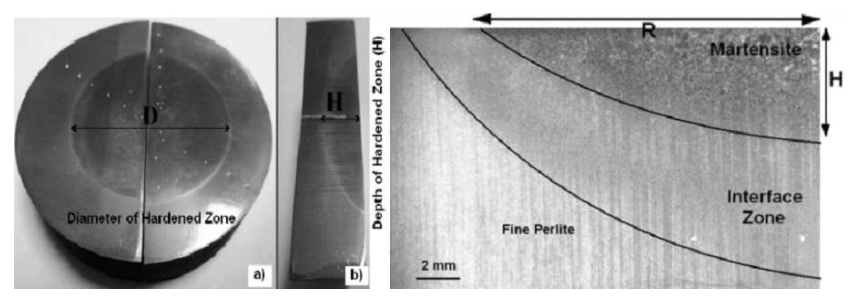

Fig. 1. Macro and stereo photograph of plasma treated surface (a), and perpendicular section to surface (b), stereo microscopy of perpendicular section view of plasma treated surface and corresponding phases (c).

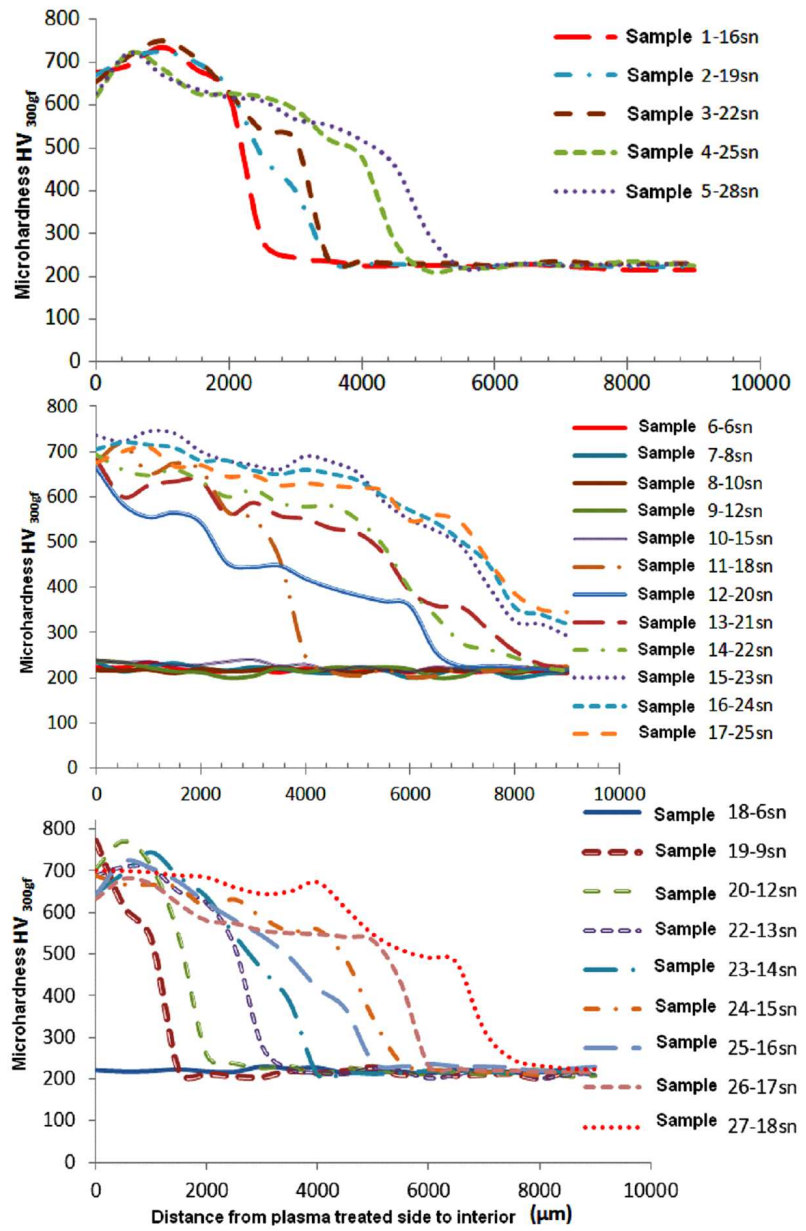

Fig. 2. Microhardness vs. distance from the plasma layer to the interior for the 4140 steel treated for several heating time and voltage.

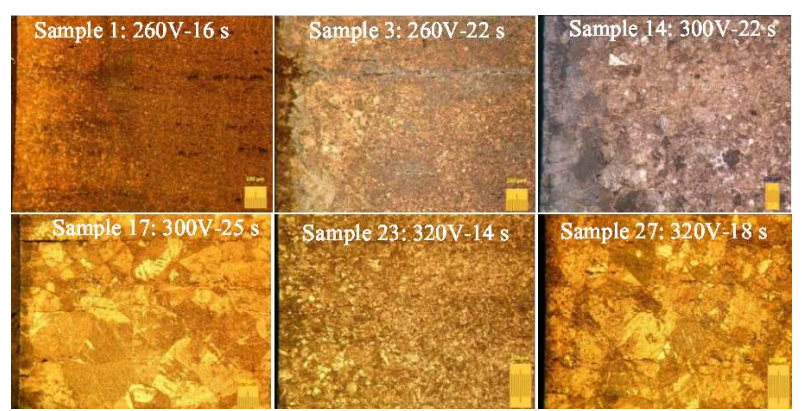

Fig. 3. Etched image of hardened samples taken from martensitic zone.

It is shown that the average size increases almost linearly with plasma electrolysis temperature. However, at high temperatures the full width at half maximum (FWHM) (Fig. 4) values tend to decrease. Decrease of FWHM can be explained by coarsening of grains because of overheating during the plasma discharge. 


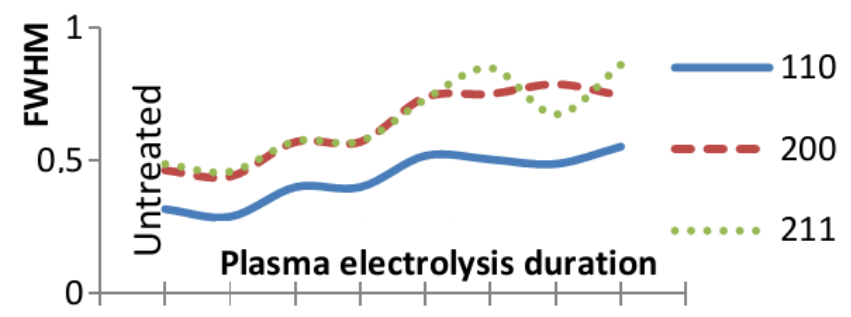

Fig. 4. FWHM values of AISI 4140 steel after and before plasma electrolysis.

\section{Conclusion}

As the applied potential and treatment duration were gradually increased, in a very short time, such as 10$30 \mathrm{~s}, 700-800 \mathrm{HV}$ hardness was obtained. An increase in voltage led to a proportional rise in the current and reduced the heating time required to reach the desired temperature. Plasma electrolytically hardened samples were etched in $60 \% \mathrm{HCl}, 30 \% \mathrm{HNO}_{3}, 5 \% \mathrm{HF}, 5 \% \mathrm{H}_{2} \mathrm{O}$ for $5 \mathrm{~s}$ then immersed in $5 \%$ picric acid, $5 \% \mathrm{HCl}, 90 \%$ ethanol to reveal microstructures. The grain boundary and lath martensitic structure were revealed for the samples heated above $450{ }^{\circ} \mathrm{C}$. On the plasma side coarse grain size was observed for the samples which heated excessive temperature such as $900-1000^{\circ} \mathrm{C}$. On the other hand, lower plasma temperatures and heating periods gave ultrafine grain size. The finer grain size was obtained with the relatively higher voltage such as $320 \mathrm{~V}$.

\section{References}

[1] A. Yerokhin, A. Pilkington, A. Matthews, J. Mater. Proc. Technol. 210, 54 (2010)

[2] E.I. Meletis, X. Nie, F.L. Wang, J.C. Jiang, Surf. Coat. Technol. 150, 246 (2002)

[3] A.L. Yerokhin, X. Nie, A. Leyland, A. Matthews, Surf. Coat. Technol. 122, 73 (1999)

[4] L.C. Kumruoglu, A. Ozel, Mater. Manufact. Proc. 25, 923 (2010)

[5] L. Kumruoglu, Becerik, C. Alexander, D. Ozel, A. Mimaroglu, Mater. Manufact. Proc. 24, 781 (2009)

[6] http://www.industrialheating.com/Articles/ Feature_Article/BNP_GUID_9-5-2006_A.

[7] O. McPherson, http://www.wpi.edu/Pubs/ E-project/Available/E-project-042508-223025/ unrestricted/MQP_Grain_Growth.pdf April 30, 2008. 